\title{
The Therapeutic Role of Guided Mental Imagery in Treating Stress and Insomnia: A Neuropsychological Perspective
}

\author{
Ravinder Jerath ${ }^{*}$, Connor Beveridge ${ }^{1}$, Michael Jensen ${ }^{2}$, Ruchir Paladiya ${ }^{3}$ \\ ${ }^{1}$ Charitable Medical Healthcare Foundation, Augusta, GA, USA \\ ${ }^{2}$ Department of Medical Illustration, College of Allied Health Sciences, Augusta University, Augusta, GA, USA \\ ${ }^{3}$ B. J. Medical College, Ahmedabad, India \\ Email: *Rj605r@aol.com
}

How to cite this paper: Jerath, R., Beveridge, C., Jensen, $M$. and Paladiya, R. (2020) The Therapeutic Role of Guided Mental Imagery in Treating Stress and Insomnia: A Neuropsychological Perspective. Open Journal of Medical Psychology, 9, 21-39.

https://doi.org/10.4236/ojmp.2020.91003

Received: November 20, 2019

Accepted: December 23, 2019

Published: December 26, 2019

Copyright $\odot 2020$ by author(s) and Scientific Research Publishing Inc. This work is licensed under the Creative Commons Attribution International License (CC BY 4.0).

http://creativecommons.org/licenses/by/4.0/

\section{cc) (i) Open Access}

\begin{abstract}
Excessive distress and insomnia are much too common in the modern world and often lead to a myriad of detrimental effects including loss of cognitive ability and even physical ailments such as cancer. Current pharmaceutical treatments can be addictive, detrimental to health, and in the case of insomnia don't produce naturalistic sleep. We present a viewpoint on a potential adjunctive treatment of distress and insomnia that harnesses specific mental imagery as a component of mind/body relaxation technique. Via our perspective on the modern nature of stress and insomnia, our theoretical perspective on how specific guided mental imagery can be used to treat these ailments, and our review on the current literature on treatment with mental imagery, we hope to stimulate further research into mental health treatment with mental imagery which has traditionally been neglected. This perspective on the pathology of insomnia and distress is founded in prevailing "dysevolution" and hyper-arousal theories. Hyper-arousal is characterized in part by a vicious cycle of chronic physiological and emotional stimulation/distress. We argue for spatially based mental imagery in the form of nighttime-sky imagery to attenuate such pathology by breaking one away from a vicious cycle of stimulation and distress and discuss neuropsychological bases for its potential treatment mechanisms which include the autonomic nervous system and a phenomenal foundation of conscious cognition.
\end{abstract}

\section{Keywords}

Mental Imagery, Guided Imagery, Insomnia, Chronic Stress, Hyperarousal, Vicious Cycle 


\section{Introduction}

In the United States, an estimated 110,000 vehicular crashes and 6500 deaths are attributable to sleep-related fatigue [1] with well over 70 million Americans suffering from chronic to occasional insomnia which significantly interferes with daily life [2]. This has been estimated to cost Americans reaching near half a trillion dollars per year in reduced productivity and work hours (10 million hours lost), not including medical and other costs [3]. A great deal can be said about the negative effects of sleep-deprivation of which include mental deficits and disorders such as increased incidents and severity of depression [4], addiction [5], anxiety [6], attention and learning difficulties [7], and physical ailments such as obesity [8], heart disease [5], and even cancer [9]. The pharmaceutical drugs such as the z-drugs used to promote sleep in insomniacs not only can be habit-forming [10], increase mortality chances and mental issues such as depression [11], but do not produce the naturalistic sleep or sleep architecture needed for the full health necessities of sleep [12] [13] [14].

In opposition to "good stress", or eustress, which is exhilarating and occurs in response to short-term challenging events over which we may master or leave a sense of accomplishment, distress is "bad stress" which occurs over more prolonged events where we have little control and are draining, exhausting, and/or dangerous [15]. Chronic distress can be promoted by insomnia and insomnia promoted by chronic distress [16]. Like insomnia, there are many negative health outcomes due to chronic distress in part due to the harmful effects of long-term exposure to stress hormones [17]. The sympathetic nervous system is in a large part responsible for their release [17]. Some of these negative health outcomes include accelerated aging [18] [19], heart disease, panic disorders, depression, anxiety, anger [20] [21], neurotoxicity, cognitive impairment [22] [23], gastrointestinal issues [24], and autoimmune disease [25]. The ailments brought about by distress and insomnia can cause further distress and/or insomnia, producing a vicious cycle which can be difficult to escape [25]. Pharmaceutical treatments for chronic stress and anxiety such as benzodiazepines have many of the same negative side effects as insomnia drugs [26].

In this article, we discuss and promote a non-pharmaceutical treatment and non-pharmaceutical treatments in general for hyperarousal based insomnia and chronic distress that focus on stopping the vicious cycle just mentioned. Hyperarousal, a key component of all modern etiological models of insomnia [27], is thought to be a 24-hr condition in which patients are near constantly aroused physiologically and often emotionally/psychologically, even during sleep [16]. Several factors may contribute to the onset and maintenance of a viscous cycle of arousal including neurotic personality traits, stressful life events, sleep reactivity (the degree to which stress disrupts sleep) [27], genetic predispositions, and age-related homeostatic decline [16]. Primary sleep disorders such as sleep apnea do not appear to significant cause of insomnia [28]. Medical disorders causing chronic pain or discomfort as well as substance abuse may cause chronic in- 
somnia/distress [29] and we note the guided imagery we describe would likely not be as effective in treating insomnia caused by these conditions. Stressful events are a main trigger for the initiation of such a cycle and insomniacs are less able to deal with such events, possibly due to poor personal relationships and self-perceptions [29]. Chronic insomniacs with such arousal problems and inability to deal with stress positively tend to be more prone to depression, anxious rumination, lack the ability to inhibit emotions, and lack the ability to express their anger [30].

We address the role of a spatial and naturalistic based form of mental imagery, nighttime-sky imagery as a part of a greater mind/body intervention in treating such a viscous cycle. When experiencing a nighttime-sky, one is looking into a potentially infinite expanse of space. We assert a neuropsychological perspective on why such a spatial form of imagery is most effective in treating hyperarousal and neurotic rumination based on a prominent neuropsychological theory in consciousness and cognition which posits that a three-dimensional (3D) coordinate matrix is the foundation of one's conscious and cognitive reality [16] [31] [32]. Mind/body relaxation techniques which include a synergistic combination of methods such as deep breathing, meditation, and mental imagery have been reported as the most favored and effective non-pharmacological interventions by patients [21]. In addition to mental imagery, we hope to persuade healthcare providers to when possible aim for non-pharmaceutical interventions for stress and insomnia such as various meditation techniques [33] [34] [35] [36] [37], deep breathing techniques [38] [39] [40], exercise, lifestyle alterations, reduced evening light exposure, reduced evening temperature, and various forms of stress management [41] [42] [43] [44] [45].

\section{A Vicious Cycle}

We address the origins of chronic stress and insomnia here largely from the basis of an evolutionary perspective, namely the evolutionary mismatch hypothesis. This hypothesis identifies the pathophysiology of many human diseases as resulting from traits that were once advantageous to our cave dwelling and primal ancestors but that are maladaptive in modern life, thus a mismatch between environments exists [46] [47]. For instance, we have evolved over millions of years to crave high calorie (sugars and fats) foods due to the scarcity of food in our ancestor's environments, however today we have large surpluses of food and these primal cravings have led us to ever increasing rates of obesity [47]. Chronic stress leads to a state of sustained autonomic imbalance [48]. Such a mismatch due to the frenetic nature of modern life has led to maladaptations in the daily functioning of our autonomic nervous system due to stress, specifically a tendency towards the sympathetic mode which is evolutionarily purposed for short-term activation [49] [50]. The toxic and long-term arousal of the sympathetic system, a component of hyper-arousal, likely further promotes the development and maintenance of many modern cases of chronic distress [50], and 
insomnia [38] [39]. Arousal stimulates the sympathetic nervous system and the sympathetic nervous system promotes arousal [48].

Chronic insomnia and/or distress has been previously described as arising from a vicious cycle of emotional and physiological arousal (in which the arousal causes more arousal in a snowball like effect) due to personality and neurophysiological traits [29] [51]. Those who don't cope well with stress tend to be discontent and have poor self-perspectives and interpersonal relationships [29]. One older hypothesis describing such a vicious cycle associates insomnia (and we assert describes chronic stress) with inhibited and repressive personality traits [52] which after initiation by a stressful life event, may lead to a state of constant emotional arousal which results in physiological arousal [16] [29]. This "Internalization Hypothesis" describes these patients as handling stress by internalizing emotions [16]. They ruminate about personal issues such as work and relationships [16]. As a result of their constant arousal, they lose sleep and further become fearful of sleeplessness, intensifying their emotional arousal and perpetuating their insomnia (and stress) [29] [51]. This vicious cycle thus becomes independent of its origin over time [16]. Most insomnia (and we assert promoting chronic stress) has also been described as a result of general twenty-four hour central nervous system hyperarousal rather than a nighttime-specific sleep loss disorder [16] [53] [54] [55]. Sleep-loss (and chronic stress) may thus be manifestations of such hyperarousal [16] which resembles normal temporary anxiety or emotional distress [56].

A 24-hr hyperarousal disorder neurologically involves an increase in activity in the reticular activating system which is a complex and diffuse network of projections from multiple brainstem sources [57]. A complex arrangement of neurotransmitter-specific signaling in this system such as an increase in aminergic input compared to cholinergic largely determines arousal level [57] [58]. This reticular system is thus involved in alertness, wakefulness, and even emotional arousal via its projections to the cortex [57] [59]. Descending projections from the reticular formation to autonomic centers of the brainstem and spinal cord can increase bodily arousal such as an increase in heart and respiration rate [60]. Other brainstem regions such as the locus coeruleus also play a role in arousal and should be considered when determining a neurological model of hyperarousal [61].

There is an intimate relationship between stress and insomnia as they may promote or cause one other, potentially feeding each other in a vicious cycle. Good sleep causes emotional experiences to be remembered more positively and less distressful than when they occurred and compared to after poor sleep [56]. Exposure to emotional stimuli results in more autonomic arousal and erratic emotional responses in those getting little/no sleep compared to those who got good sleep [62] [63]. Chronic insomnia may result in a lasting deficiency in the ability to neurologically downregulate distress [64], and unlike good sleepers, insomniacs are unable to dissociate limbic activity and autonomic reactivity from distressing and/or shameful long-term memories [56]. They may be 
"haunted by the past". We have described potential mechanisms in which respiration may play a role in arousal activity of the brain via cardio-respiratory synchronization. We in part assert the power of mental imagery in synergistic combination with the mind/body technique of deep-slow breathing via such a mechanism in which cardiorespiratory feedback from the body modulates signaling among the reticular activating system and hypothalamus and via modulation of the autonomic nervous system [65] [66]. We assert mental imagery may provide an adjunctive means to attenuate the viscous cycle and will now review research supporting the therapeutic power of mental imagery in general.

\section{Guided Mental Imagery for Therapy}

Mental imagery, phenomenal (we focus on visual) representations without a direct stimulus, functions cognitively and neurologically as a weak form of stimulus perception [67]. Imagined stimuli can be considered as a type of top-down perception [67] and has similar effects as real stimuli on physiology such as on pupil dilation [68]. Mental Imagery is increasingly being recognized via research and theory as playing an important role in mental health treatment including stress/anxiety and insomnia treatment [67] [69] [70] [71] [72]. Guided imagery therapy has also shown effectiveness in treating chronic pain [73], fatigue [70] [74], food cravings [75] [76], arthritis [77], hypertension [78], and even fibromyalgia [79]. Positive mental imagery (imagining a nice place) has been reported by patients as the most effective relaxation technique and the most likely to be used at home [80]. In addition to being cost-effective, imagery of beautiful scenes may improve quality of life [81]. It may distract patients away from their pain, stress, and personal/emotional problems (such as fear of sleeplessness) and teach them general self-regulatory coping skills to assist with these problems [69] [82]. "Private" imagery or that which isolates one from social aspects of life is thought to be key to effective relaxation imagery [80].

Unsurprising from an evolutionary perspective, natural environments such as a forest atmosphere or can provide relaxation/comfort, reduce stress, and promote a deep connection with nature [83]. From the same perspective, our "artificial" modern environments may create stressful feelings [83] [84]. Considering visual mental imagery and perception of actual stimuli neurologically resemble one another as early as V1 [67], mental imagery of natural environments should promote identical relaxing effects. In addition to shifting the autonomic state toward the parasympathetic, naturalistic stimuli decrease functional connectivity in hubs of the default mode network corresponding to self-referential thought processes [48]. Thus, naturalistic mental imagery may attenuate ruminative self-referential neural activity which may be the source of many distressing, depressive, and arousing thoughts [85] [86] [87].

Traditionally neglected from a treatment perspective [67], intrusive, emotional imagery matching the concerns of the individual is a distressing aspect of many mental conditions such as post-traumatic stress, depression, and anxiety 
disorders [88] [89]. Insomniacs have fewer, but a significantly greater fraction of unpleasant mental images compared to good sleepers [90]. These involuntary mental images of insomniacs are more emotionally charged compared to the "random" images of good sleepers [90]. Intrusive mental images are not just a symptom of certain mental disorders, but may actively drive the maintenance of the disorders [67] [91]. Guided mental imagery has been supported as an effective means to treat intrusive mental imagery either by producing tolerance/desensitization (voluntarily imagining stressful images) [92] or by positively transforming the intrusive imagery content [67] [93] [94]. We assert a spatially based form of mental imagery will be optimal in decelerating and even halting the vicious cycle discussed by dissociating one from the incessant rumination on personal/professional stressors and distressing memories which feed further emotional and physiological arousal. This may be effective as the foundation of consciousness and cognition is a spatial, internal, "virtual" reality.

\section{A Phenomenal and Cognitive Foundation}

We and several consciousness researchers have proposed a fundamental phenomenological and cognitive foundation to consciousness and mind. This is a subconscious and unifying, 3D "virtual", spatial coordinate matrix in which all conscious qualia are embedded and in which key cognitive mechanisms are performed [31] [32] [95] [96] [97] [98] [99]. Consciousness can be thought to be identical to the contents of this space and conscious perception occurs from the perspective of the mathematical origin or center of this space [96]. The first-person sense of self is located at this center [97] [98] [100]. This space is theorized to house a simulation or model of the internal and external world and our relationship to it [31] [101] [102] [103] [104]. Even the self can be thought of as a simulation housed within this space [98] [100]. Instead of experiencing this simulation of the self and external world as a virtual model heavily influenced by expectations and biases, we indeed experience it as if it were the actual physical world [99] [100] [103] [105]. The neurophysiological and cognitive research supporting this 3D space, world-simulation theory [106] is predominated by research into the nature of contralateral neglect syndrome [107]. Structure is proposed to be an axiom of any type of consciousness [108] and this space may provide an explanation and means for its global unity, both phenomenally and in its isomorphic neurophysiology [32] [109].

Just like all mental aspects, this virtual space has a neural equivalent and is proposed to be formed by slow neural oscillations which are a part of the global bioelectric field of the brain [109] which has been asserted to be isomorphic to consciousness and aspects of cognition [110]. Just as the virtual space connects and organizes all aspects of consciousness into a singular whole, these slow oscillations act as a foundation for higher frequency activity to form upon and thus connect and organize higher frequency activity into a global whole [111]. This includes the multimodal integration of all sensory types [109]. Several research- 
ers have investigated how slow oscillations modulate [112] [113] [114], group [115] [116], organize, and entrain faster ones [117] [118]. Slow oscillations are able to globally coordinate and unify activity in dispersed and distinct neural assemblies because they facilitate longer range communication [119] and affect greater populations of neurons than fast oscillations which act more locally within assemblies [112]. Just as the $3 \mathrm{D}$ virtual space allows distinct phenomenal qualities and objects such as a red ball to be unified into a single conscious experience, these slow oscillations allow individual neural assemblies formed by fast oscillations [120], which are likely responsible for more finely detailed aspects of consciousness and cognition, to be part of the global brain operation [111]. Thus, slow oscillations may provide a means to neurophysiologically explain the effectiveness of a spatially based form of mental imagery.

\section{Nighttime-Sky Mental Imagery as a Mind/Body Component}

In promoting a specific form of mental imagery for treatment of distress and insomnia in adjunct with other mind/body techniques, we have considered the current literature on imagery as well as prominent theory on the phenomenal and cognitive foundation of mind. We propose that nighttime-sky mental imagery is optimal for treating nighttime stress and insomnia as there is a close relationship between the two. The proposed purpose of using this type of imagery may provide insight into treating daytime stress and may also be appropriate for daytime stress. This type of imagery may work to reverse the vicious cycle described which is proposed to perpetuate hyper-arousal. Although this and other mental imagery would be helpful during the day, targeting this arousal when it is time to sleep would be most optimal as it would negate many of the stressful effects of sleep deprivation. This relaxation may be initiated by replacing negative emotions and thoughts which fuel arousal with relaxing feelings of awe and wonder induced by the nighttime sky. As discussed on the effects of naturalistic images, some images (such as the image of a snake or looming shadow of a bird) are likely evolutionarily/genetically "programmed" in humans/animals to have certain emotional, neurophysiological, and physical responses relevant to survival [121] [122] [123] [124] [125]. Such phylogenetic "memories" are no less relevant than those acquired by experience and likely have similar biological underpinnings as memories established throughout life [126]. In addition to the profound effects of light and the lack of it on the circadian rhythm [127], we assert the image of the nighttime sky may also be phylogenetic, possibly stimulating relaxation and/or the production of melatonin.

Mental imagery preserves the spatial characteristics of the environment that is being mentally represented [128]. Even eye movement and focus reflect the spatial content of the mental image [128]. Assuming that a $3 \mathrm{D}$ virtual space is a cognitive foundation of mind, and given that all personal and social problems which may cause distress and insomnia occur in a space "immediate" to the 
person's real or imaged perspective, we assert that diverting attention away immediate space will attenuate the stresses which occur in such immediate space. In imagining a nighttime-sky, imagining the stars is not near as important as imaging the supreme spatial vastness that one looks into when looking up into the depths of the universe. Imagining a potentially infinite expanse of space should disassociate one from the personal and social problems that occur here on earth (Figure 1) and provide a "private" experience shown to be key to relaxing imagery [80]. Although temporary, this technique may temporarily but significantly break one out of the vicious cycle of stress and arousal discussed which builds upon itself, thus allowing one to get the sleep needed to further break down the cycle (Figure 2). We hope to inspire research into this and potentially other forms of spatially based imagery. Although such research does not currently exist, anecdotal reports of success from the authors and author's (RJ) medical patients warrant investigation.

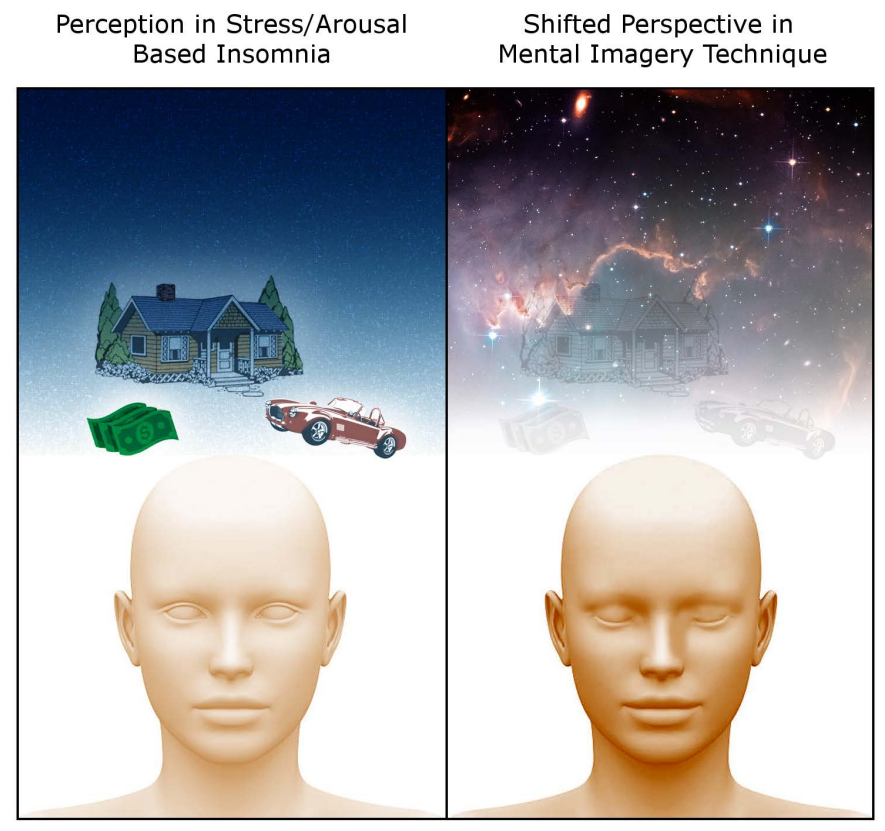

Figure 1. Spatially based disassociation from stressors. This graphic depicts in an easy to understand manner the shift in consciousness brought about by nighttime sky imagery. The mechanism of this treatment in part assumes that a virtual 3D coordinate space is the foundation of consciousness and conscious cognition. Other mechanisms are discussed in the article. In the person emotionally aroused at nighttime by various personal, professional, and social problems, their attention lies in immediate space as this is where the distressing imagery and thoughts of their problems are spatially situated. In the images shown, these problems may include social problems at home, problems paying bills, or keeping up with a vehicle. When one elicits nighttime-sky imagery in them or imagine what heavenly bodies lie beyond it in the vastness of space. Their spatial attention gets shifted to the vastness or potentially infinite spatial expanse of outer space in which no stressful problems are spatially situated. We propose this will dissociate one from these problems and promote positive emotions of wonder and awe which counteract the distressing and arousing emotions which promote a vicious cycle of insomnia and distress (Original image by Michael Jensen). 


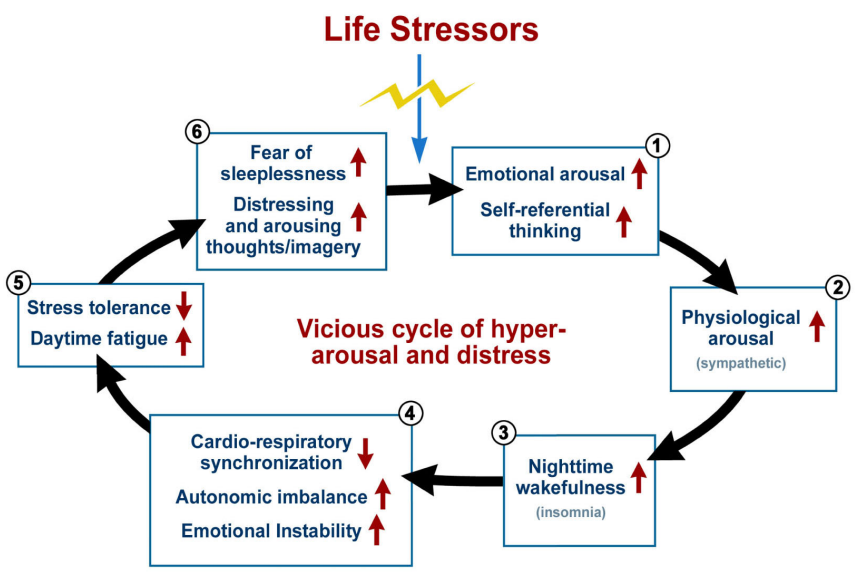

(a)

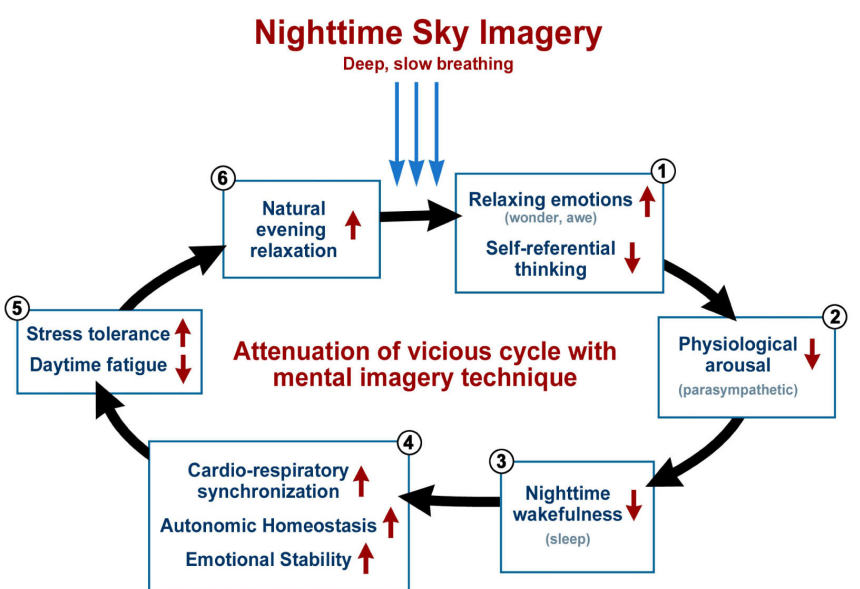

(b)

Figure 2. A viscous cycle and its attenuation with a mind/body technique. This image illustrates the phases of a vicious cycle of the intimately associated conditions of chronic distress and insomnia which feed upon one another. The top cycle (a) illustrates the pathology discussed of such a viscous cycle and the bottom one (b) shows its attenuation. Cycle A begins with a significant life stressor which sparks intense emotional (or cognitive) arousal and self-referential thoughts. This in turn causes physiological arousal of the mind and body which causes one to not be able to sleep. This arousal of the body is mediated by the sympathetic branch of the autonomic nervous system and includes increased respiration and heart rates. The lack of sleep leads to problems during the day, some of which are associated with decreased cardio-respiratory synchronization. Daytime emotional instability and hyperarousal of the sympathetic nervous system due to sleep loss in part lead to the lack of ability to handle common stressors. Personal problems brought about by daytime Fatigue (differentiated from wakefulness) and increased stress brought about by sleep loss lead one to fear sleep. In addition, this stress lasts into the evening and the distressing thoughts/images they experience restart the cycle with nighttime arousal and thus further sleep loss. In image (a), the jagged cutoff from the "Life Stressors" initiator indicates that at the point the cycle comes full circle, the significant life stressors are no longer needed and the cycle can maintain itself. Cycle (b) essentially shows the "deceleration" of cycle A. By reducing emotional arousal via essentially dissociating one from their stressors, physiological arousal is reduced (with the assistance of deep-slow breathing), allowing one to relax and achieve sleep. Good sleep then promotes healthy emotional reactivity and stress tolerance, eliminating the fear of sleeplessness and promoting normal evening relaxation (Original image by Michael Jensen). 
Considering that the mind not only affects the body, but the body affects the mind [129] [130], these temporary breaks in arousal via imagery may reduce physiological arousal thus further decelerating the vicious cycle. By including deep-slow breathing in combination with imagery such deceleration may be synergistically magnified through promoting a more parasympathetic state of the autonomic nervous system. Good sleep may thus be acquired which then further promotes parasympathetic tone during the day [131]. The brain recognizes the state of the body and responds appropriately. When we are stressed or aroused, the brain produces quick, irregular respiration via the sympathetic system while simultaneously recognizing this somatic state causing further arousal. Along with other mechanisms, by voluntarily slowing and making our respiration more regular, the brain may recognize this as a calm state thus calming arousal. This follows the somatic marker hypothesis and other theories which describe a major source of emotion as feedback from reflexively activated bodily activity [129] [132] [133] [134].

\section{Conclusion}

Mind/body stress reduction programs that include a combination of deep breathing, meditation, and mental imagery have been shown to be the most effective non-pharmacological interventions to reduce stress, and so we promote such imagery discussed here to be used alongside other mind/body techniques as they appear to work synergistically. We have provided a perspective on the neuropsychological role of a specific type of mental imagery, nighttime sky imagery, in this synergistic therapy. We have discussed the nature of a vicious cycle of distress and/or insomnia and how mental imagery may assist in breaking this cycle. The synergistic mind/body treatments may be more effective at diminishing hyperarousal as they target not only the brain but the body likely via the autonomic nervous system and somatic recognition by the brain. By providing neuropsychological backing for treatment with a specific type of imagery (nighttime-sky) to be used in conjunction with deep-slow breathing and/or meditation, we hope to inspire research into traditionally neglected mental imagery and promote the use of mind/body techniques over pharmacological interventions.

\section{Author Contributions Statement}

Theory Developed by RJ with some writing and background research. The Majority of the Manuscript and background research was done by CB. The Images were made originally by MJ. A minority of background research and the manuscript was done by RP.

\section{Conflicts of Interest}

The authors declare no conflict of interest.

\section{References}

[1] Tefft, B.C. (2014) Prevalence of Motor Vehicle Crashes Involving Drowsy Drivers, 
United States, 2009-2013.

[2] Purves, D., Augustine, G.J., Fitzpatrick, D., et al. (2018) Neuroscience. 6th Edition, Sinauer Associates, New York.

[3] Hafner, M., Stepanek, M., Taylor, J., et al. (2017) Why Sleep Matters-The Economic Costs of Insufficient Sleep: A Cross-Country Comparative Analysis. Rand Health Quarterly, 6, 11-11.

[4] CDC Short Sleep Duration among US Adults-Data and Statistics (2017) Sleep and Sleep Disorders.

[5] Westerlund, A., Bellocco, R., Sundström, J., et al. (2013) Sleep Characteristics and Cardiovascular Events in a Large Swedish Cohort. European Journal of Epidemiology, 28, 463-473. https://doi.org/10.1007/s10654-013-9802-2

[6] Pires, G.N., Bezerra, A.G., Tufik, S. and Levy, M. (2016) Effects of Acute Sleep Deprivation on State Anxiety Levels: A Systematic Review and Meta-Analysis. Sleep Medicine, 24, 109-118. https://doi.org/10.1016/j.sleep.2016.07.019

[7] Alhola, P. and Polo-Kantola, P. (2007) Sleep Deprivation: Impact on Cognitive Performance. Neuropsychiatric Disease and Treatment, 3, 553-567.

[8] Hargens, T.A., Kaleth, A.S., Edwards, E.S. and Butner, K.L. (2013) Association between Sleep Disorders, Obesity, and Exercise: A Review. Nature and Science of Sleep, 5, 27-35. https://doi.org/10.2147/NSS.S34838

[9] De Lorenzo, B.H.P., Novaes e Brito, R.R., Paslar Leal, T., et al. (2018) Chronic Sleep Restriction Impairs the Antitumor Immune Response in Mice. Neuroimmunomodulation, 25, 59-67. https://doi.org/10.1159/000490352

[10] Carlstedt, R.A. (2009) Handbook of Integrative Clinical Psychology, Psychiatry, and Behavioral Medicine: Perspectives, Practices, and Research. Springer Publishing Company, New York.

[11] Kripke, D.F. (2016) Mortality Risk of Hypnotics: Strengths and Limits of Evidence. Drug Safety, 39, 93-107. https://doi.org/10.1007/s40264-015-0362-0

[12] Manconi, M., Ferri, R., Miano, S., et al. (2017) Sleep Architecture in Insomniacs with Severe Benzodiazepine Abuse. Clinical Neurophysiology, 128, 875-881. https://doi.org/10.1016/j.clinph.2017.03.009

[13] Gunja, N. (2013) The Clinical and Forensic Toxicology of Z-Drugs. Journal of Medical Toxicology, 9, 155-162. https://doi.org/10.1007/s13181-013-0292-0

[14] Bastien, C.H., Le Blanc, M., Carrier, J. and Morin, C.M. (2003) Sleep EEG Power Spectra, Insomnia, and Chronic Use of Benzodiazepines. Sleep, 26, 313-317. https://doi.org/10.1093/sleep/26.3.313

[15] McEwen, B.S. (2007) Physiology and Neurobiology of Stress and Adaptation: Central Role of the Brain. Physiological Reviews, 87, 873-904. https://doi.org/10.1152/physrev.00041.2006

[16] Basta, M., Chrousos, G.P., Vela-Bueno, A. and Vgontzas, A.N. (2007) Chronic Insomnia and Stress System. Sleep Medicine Clinics, 2, 279-291. https://doi.org/10.1016/j.jsmc.2007.04.002

[17] Carlson, N.R. (2013) Physiology of Behavior. 11th Edition, Pearson, Boston, MA.

[18] Quinlan, J., Tu, M.T., Langlois, É.V., et al. (2014) Protocol for a Systematic Review of the Association between Chronic Stress during the Life Course and Telomere Length. Systematic Reviews, 3, 40. https://doi.org/10.1186/2046-4053-3-40

[19] Wikgren, M., Maripuu, M., Karlsson, T., et al. (2012) Short Telomeres in Depression and the General Population Are Associated with a Hypocortisolemic State. Biological Psychiatry, 71, 294-300. https://doi.org/10.1016/j.biopsych.2011.09.015 
[20] Cohen, S., Janicki-Deverts, D. and Miller, G.E. (2007) Psychological Stress and Disease. The Journal of the American Medical Association, 298, 1685-1687. https://doi.org/10.1001/jama.298.14.1685

[21] Iglesias, S.L., Azzara, S., Argibay, J.C., et al. (2012) Psychological and Physiological Response of Students to Different Types of Stress Management Programs. American Journal of Health Promotion, 26, e149-e158. https://doi.org/10.4278/ajhp.110516-QUAL-199

[22] Jung, S., Choe, S., Woo, H., et al. (2019) Autophagic Death of Neural Stem Cells Mediates Chronic Stress-Induced Decline of Adult Hippocampal Neurogenesis and Cognitive Deficits. Autophagy, 2019, 1-19. https://doi.org/10.1080/15548627.2019.1630222

[23] Yuen, E.Y., Wei, J., Liu, W., et al. (2012) Repeated Stress Causes Cognitive Impairment by Suppressing Glutamate Receptor Expression and Function in Prefrontal Cortex. Neuron, 73, 962-977. https://doi.org/10.1016/j.neuron.2011.12.033

[24] Gao, X., Cao, Q., Cheng, Y., et al. (2018) Chronic Stress Promotes Colitis by Disturbing the Gut Microbiota and Triggering Immune System Response. Proceedings of the National Academy of Sciences of the United States of America, 115, E2960-E2969. https://doi.org/10.1073/pnas.1720696115

[25] Stojanovich, L. and Marisavljevich, D. (2008) Stress as a Trigger of Autoimmune Disease. Autoimmunity Reviews, 7, 209-213. https://doi.org/10.1016/j.autrev.2007.11.007

[26] Kumar, A., Rinwa, P., Kaur, G. and Machawal, L. (2013) Stress: Neurobiology, Consequences and Management. Journal of Pharmacy \& Bioallied Sciences, 5, 91-97. https://doi.org/10.4103/0975-7406.111818

[27] Kalmbach, D.A., Cuamatzi-Castelan, A.S., Tonnu, C.V., et al. (2018) Hyperarousal and Sleep Reactivity in Insomnia: Current Insights. Nature and Science of Sleep, 10, 193-201. https://doi.org/10.2147/NSS.S138823

[28] Kales, A., Vela-Bueno, A., Bixler, E.O., et al. (1982) Biopsychobehavioral Correlates of Insomnia, Part 1: Role of Sleep Apnea and Nocturnal Myoclonus. Psychosomatics, 23, 589-600. https://doi.org/10.1016/S0033-3182(82)73359-6

[29] Kales, A. and Kales, J. (1984) Evaluation and Treatment of Insomnia. Oxford University Press, New York. https://doi.org/10.1097/00002826-198406001-00405

[30] Kales, A., Caldwell, A.B., Soldatos, C.R., Bixler, E. and Kales, J. (1983) Biopsychobehavioral Correlates of Insomnia. II. Pattern Specificity and Consistency with the Minnesota Multiphasic Personality Inventory. Psychosomatic Medicine, 45, 341-356. https://doi.org/10.1097/00006842-198308000-00008

[31] Jerath, R., Crawford, M.W. and Barnes, V.A. (2015) A Unified 3D Default Space Consciousness Model Combining Neurological and Physiological Processes that Underlie Conscious Experience. Frontiers in Psychology, 6, 1204. https://doi.org/10.3389/fpsyg.2015.01204

[32] Fingelkurts, A.A., Fingelkurts, A.A. and Neves, C.F.H. (2010) Natural World Physical, Brain Operational, and Mind Phenomenal Space-Time. Physics of Life Reviews, 7, 195-249. https://doi.org/10.1016/j.plrev.2010.04.001

[33] Winbush, N.Y., Gross, C.R. and Kreitzer, M.J. (2007) The Effects of Mindfulness-Based Stress Reduction on Sleep Disturbance: A Systematic Review. Explore, 3, 585-591. https://doi.org/10.1016/j.explore.2007.08.003

[34] Tooley, G.A., Armstrong, S.M., Norman, T.R. and Sali, A. (2000) Acute Increases in Night-Time Plasma Melatonin Levels Following a Period of Meditation. Biological Psychology, 53, 69-78. https://doi.org/10.1016/S0301-0511(00)00035-1 
[35] Abrams, A.I. and Siegel, L.M. (1978) The Transcendental Meditation Program and Rehabilitation at Folsom State Prison: A Cross-Validation Study. Correctional Psychologist, 5, 3-20. https://doi.org/10.1177/009385487800500101

[36] Garcia, M.C., Kozasa, E.H., Tufik, S., Mello, L.E.A. and Hachul, H. (2018) The Effects of Mindfulness and Relaxation Training for Insomnia (MRTI) on Postmenopausal Women: A Pilot Study. Menopause, 25, 992-1003. https://doi.org/10.1097/GME.0000000000001118

[37] Jerath, R., Barnes, V.A. and Crawford, M.W. (2014) Mind-Body Response and Neurophysiological Changes during Stress and Meditation: Central Role of Homeostasis. Journal of Biological Regulators \& Homeostatic Agents, 28, 545-54.

[38] Jerath, R., Beveridge, C. and Barnes, V.A. (2019) Self-Regulation of Breathing as an Adjunctive Treatment of Insomnia. Frontiers in Psychiatry, 9, 780. https://doi.org/10.3389/fpsyt.2018.00780

[39] Tsai, H.J., Kuo, T.B.J., Lee, G.-S. and Yang, C.C.H. (2015) Efficacy of Paced Breathing for Insomnia: Enhances Vagal Activity and Improves Sleep Quality. Psychophysiology, 52, 388-396. https://doi.org/10.1111/psyp.12333

[40] Jerath, R., Crawford, M.W., Barnes, V.A. and Harden, K. (2015) Self-Regulation of Breathing as a Primary Treatment for Anxiety. Applied Psychophysiology and Biofeedback, 40, 107-115. https://doi.org/10.1007/s10484-015-9279-8

[41] Weiss, M.D., Wasdell, M.B., Bomben, M.M., Rea, K.J. and Freeman, R.D. (2006) Sleep Hygiene and Melatonin Treatment for Children and Adolescents with ADHD and Initial Insomnia. Journal of the American Academy of Child \& Adolescent Psychiatry, 45, 512-519. https://doi.org/10.1097/01

[42] Gellis, L.A. and Lichstein, K.L. (2009) Sleep Hygiene Practices of Good and Poor Sleepers in the United States: An Internet-Based Study. Behavior Therapy, 40, 1-9. https://doi.org/10.1016/j.beth.2008.02.001

[43] O’Donnell, S. and Driller, M.W. (2017) Sleep-Hygiene Education Improves Sleep Indices in Elite Female Athletes. International Journal of Exercise Science, 10, 522-530.

[44] Bogdanov, S., Naismith, S. and Lah, S. (2017) Sleep Outcomes Following Sleep-Hygiene-Related Interventions for Individuals with Traumatic Brain Injury: A Systematic Review. Brain Injury, 31, 422-433. https://doi.org/10.1080/02699052.2017.1282042

[45] Al-Kandari, S., Alsalem, A., Al-Mutairi, S., et al. (2017) Association between Sleep Hygiene Awareness and Practice with Sleep Quality among Kuwait University Students. Sleep Health, 3, 342-347. https://doi.org/10.1016/j.sleh.2017.06.004

[46] Gluckman, P. and Hanson, M. (2013) Mismatch: The Lifestyle Diseases Timebomb. Oxford University Press, Oxford.

[47] Lieberman, D.E. (2013) The Story of the Human Body: Evolution, Health, and Disease. Pantheon, New York.

[48] Gould van Praag, C.D., Garfinkel, S.N., Sparasci, O., et al. (2017) Mind-Wandering and Alterations to Default Mode Network Connectivity When Listening to Naturalistic versus Artificial Sounds. Scientific Reports, 7, 45273. https://doi.org/10.1038/srep45273

[49] Giphart, R. and Vugt, M.V. (2018) Mismatch: How Our Stone Age Brain Deceives Us Every Day (and What We Can Do about It). Robinson Page, London.

[50] Nesse, R.M., Bhatnagar, S. and Ellis, B.J. (2016) Evolutionary Origins and Functions of the Stress Response System. In: Stress. Concepts, Cognition, Emotion, and Beha- 
vior, Elsevier, Amsterdam, 95-101.

https://doi.org/10.1016/B978-0-12-800951-2.00011-X

[51] Kales, A., Soldatos, C.R. and Kales, J.D. (1987) Sleep Disorders: Insomnia, Sleepwalking, Night Terrors, Nightmares, and Enuresis. Annals of Internal Medicine, 106, 582-592. https://doi.org/10.7326/0003-4819-106-4-582

[52] Kales, A., Caldwell, A.B., Preston, T.A., et al. (1976) Personality Patterns in Insomnia: Theoretical Implications. JAMA Psychiatry, 33, 1128-1134. https://doi.org/10.1001/archpsyc.1976.01770090118013

[53] Stepanski, E., Zorick, F., Roehrs, T., Young, D. and Roth, T. (1988) Daytime Alertness in Patients with Chronic Insomnia Compared with Asymptomatic Control Subjects. Sleep, 11, 54-60. https://doi.org/10.1093/sleep/11.1.54

[54] Edinger, J.D., Glenn, D.M., Bastian, L.A., et al. (2001) Sleep in the Laboratory and Sleep at Home II: Comparisons of Middle-Aged Insomnia Sufferers and Normal Sleepers. Sleep, 24, 761-770. https://doi.org/10.1093/sleep/24.7.761

[55] Bonnet, M.H. and Arand, D.L. (1995) 24-Hour Metabolic Rate in Insomniacs and Matched Normal Sleepers. Sleep, 18, 581-588.

https://doi.org/10.1093/sleep/18.7.581

[56] Wassing, R., Schalkwijk, F., Lakbila-Kamal, O., et al. (2019) Haunted by the Past: Old Emotions Remain Salient in Insomnia Disorder. Brain, 142, 1783-1796. https://doi.org/10.1093/brain/awz089

[57] Edlow, B.L., Takahashi, E., Wu, O., et al. (2012) Neuroanatomic Connectivity of the Human Ascending Arousal System Critical to Consciousness and Its Disorders. Journal of Neuropathology and Experimental Neurology, 71, 531-546. https://doi.org/10.1097/NEN.0b013e3182588293

[58] Purves, D., Augustine, G.J., Fitzpatrick, D., et al. (2018) Cortical States, in Neuroscience. Sinauer Associates, New York, 651.

[59] Yeo, S.S., Chang, P.H. and Jang, S.H. (2013) The Ascending Reticular Activating System from Pontine Reticular Formation to the Thalamus in the Human Brain. Frontiers in Human Neuroscience, 7, 416-416. https://doi.org/10.3389/fnhum.2013.00416

[60] Khurana, I. (2005) Textbook of Medical Physiology. Elsevier India, Up, India.

[61] Aston-Jones, G., Chen, S., Zhu, Y. and Oshinsky, M.L. (2001) A Neural Circuit for Circadian Regulation of Arousal. Nature Neuroscience, 4, 732-738. https://doi.org/10.1038/89522

[62] Cunningham, T.J., Crowell, C.R., Alger, S.E., et al. (2014) Psychophysiological Arousal at Encoding Leads to Reduced Reactivity But Enhanced Emotional Memory Following Sleep. Neurobiology of Learning and Memory, 114, 155-164. https://doi.org/10.1016/j.nlm.2014.06.002

[63] van der Helm, E., Yao, J., Dutt, S., et al. (2011) REM Sleep Depotentiates Amygdala Activity to Previous Emotional Experiences. Current Biology, 21, 2029-2032. https://doi.org/10.1016/j.cub.2011.10.052

[64] Tempesta, D., Socci, V., De Gennaro, L. and Ferrara, M. (2018) Sleep and Emotional Processing. Sleep Medicine Reviews, 40, 183-195. https://doi.org/10.1016/j.smrv.2017.12.005

[65] Jerath, R., Harden, K., Crawford, M., Barnes, V.A. and Jensen, M. (2014) Role of Cardiorespiratory Synchronization and Sleep Physiology: Effects on Membrane Potential in the Restorative Functions of Sleep. Sleep Medicine, 15, 279-288. https://doi.org/10.1016/j.sleep.2013.10.017 
[66] Jerath, R., Cearley, S.M. and Jensen, M. (2016) Widespread Membrane Potential Changes and Cardiorespiratory Synchronization Involved in Anxiety and Sleep-Wake Transitions. Journal of Biological Regulators \& Homeostatic Agents, 30, 935-944.

[67] Pearson, J., Naselaris, T., Holmes, E.A. and Kosslyn, S.M. (2015) Mental Imagery: Functional Mechanisms and Clinical Applications. Trends in Cognitive Sciences, 19, 590-602. https://doi.org/10.1016/j.tics.2015.08.003

[68] Laeng, B. and Sulutvedt, U. (2013) The Eye Pupil Adjusts to Imaginary Light. Psychological Science, 25, 188-197. https://doi.org/10.1177/0956797613503556

[69] Kwekkeboom, K.L., Abbott-Anderson, K. and Wanta, B. (2010) Feasibility of a Patient-Controlled Cognitive-Behavioral Intervention for Pain, Fatigue, and Sleep Disturbance in Cancer. Oncology Nursing Forum, 37, E151-E159. https://doi.org/10.1188/10.ONF.E151-E159

[70] Nooner, A.K., Dwyer, K., De Shea, L., et al. (2016) Using Relaxation and Guided Imagery to Address Pain, Fatigue, and Sleep Disturbances: A Pilot Study. Clinical Journal of Oncology Nursing, 20,547-552. https://doi.org/10.1188/16.CJON.547-552

[71] Beizaee, Y., Rejeh, N., Heravi-Karimooi, M., et al. (2018) The Effect of Guided Imagery on Anxiety, Depression and Vital Signs in Patients on Hemodialysis. Complementary Therapies in Clinical Practice, 33, 184-190. https://doi.org/10.1016/j.ctcp.2018.10.008

[72] Howland, L.C., Jallo, N., Connelly, C.D. and Pickler, R.H. (2017) Feasibility of a Relaxation Guided Imagery Intervention to Reduce Maternal Stress in the NICU. Journal of Obstetric, Gynecologic \& Neonatal Nursing, 46, 532-543. https://doi.org/10.1016/j.jogn.2017.03.004

[73] Lewandowski, W., Jacobson, A., Palmieri, P.A., Alexander, T. and Zeller, R. (2010) Biological Mechanisms Related to the Effectiveness of Guided Imagery for Chronic Pain. Biological Research for Nursing, 13, 364-375. https://doi.org/10.1177/1099800410386475

[74] Menzies, V. and Jallo, N. (2011) Guided Imagery as a Treatment Option for Fatigue: A Literature Review. Journal of Holistic Nursing. Official Journal of the American Holistic Nurses' Association, 29, 279-286. https://doi.org/10.1177/0898010111412187

[75] Giacobbi, P., Long, D., Nolan, R., et al. (2018) Guided Imagery Targeting Exercise, Food Cravings, and Stress: A Multi-Modal Randomized Feasibility Trial. Journal of Behavioral Medicine, 41, 87-98. https://doi.org/10.1007/s10865-017-9876-5

[76] Hamilton, J., Fawson, S., May, J., Andrade, J. and Kavanagh, D.J. (2013) Brief Guided Imagery and Body Scanning Interventions Reduce Food Cravings. Appetite, 71, 158-162. https://doi.org/10.1016/j.appet.2013.08.005

[77] Giacobbi Jr., P.R., Stabler, M.E., Stewart, J., et al. (2015) Guided Imagery for Arthritis and Other Rheumatic Diseases: A Systematic Review of Randomized Controlled Trials. Pain Management Nursing. Official Journal of the American Society of Pain Management Nurses, 16, 792-803. https://doi.org/10.1016/j.pmn.2015.01.003

[78] Haruna, M., Matsuzaki, M., Ota, E., et al. (2019) Guided Imagery for Treating Hypertension in Pregnancy. Cochrane Database of Systematic Reviews. https://doi.org/10.1002/14651858.CD011337.pub2

[79] Zech, N., Hansen, E., Bernardy, K. and Häuser, W. (2017) Efficacy, Acceptability and Safety of Guided Imagery/Hypnosis in Fibromyalgia-A Systematic Review and Meta-Analysis of Randomized Controlled Trials. European Journal of Pain, 21, 217-227. https://doi.org/10.1002/ejp.933 
[80] Hyland, M., Halpin, D., Blake, S., et al. (2016) Preference for Different Relaxation Techniques by COPD Patients: Comparison between Six Techniques. International Journal of Chronic Obstructive Pulmonary Disease, 11, 2315-2319. https://doi.org/10.2147/COPD.S113108

[81] Shahriari, M., Dehghan, M., Pahlavanzadeh, S. and Hazini, A. (2017) Effects of Progressive Muscle Relaxation, Guided Imagery and Deep Diaphragmatic Breathing on Quality of Life in Elderly with Breast or Prostate Cancer. Journal of Education and Health Promotion, 6, 1. https://doi.org/10.4103/jehp.jehp_147_14

[82] Landier, W. and Tse, A.M. (2010) Use of Complementary and Alternative Medical Interventions for the Management of Procedure-Related Pain, Anxiety, and Distress in Pediatric Oncology: An Integrative Review. Journal of Pediatric Nursing, 25, 566-579. https://doi.org/10.1016/j.pedn.2010.01.009

[83] Tsunetsugu, Y., Park, B.-J. and Miyazaki, Y. (2009) Trends in Research Related to "Shinrin-yoku" (Taking in the Forest Atmosphere or Forest Bathing) in Japan. Environmental Health and Preventive Medicine, 15, 27. https://doi.org/10.1007/s12199-009-0091-Z

[84] Frumkin, H. (2001) Beyond Toxicity: Human Health and the Natural Environment. American Journal of Preventive Medicine, 20, 234-240. https://doi.org/10.1016/S0749-3797(00)00317-2

[85] Nejad, A., Fossati, P. and Lemogne, C. (2013) Self-Referential Processing, Rumination, and Cortical Midline Structures in Major Depression. Frontiers in Human Neuroscience, 7, 666. https://doi.org/10.3389/fnhum.2013.00666

[86] Marchand, W.R. (2012) Self-Referential Thinking, Suicide, and Function of the Cortical Midline Structures and Striatum in Mood Disorders: Possible Implications for Treatment Studies of Mindfulness-Based Interventions for Bipolar Depression. Depression Research and Treatment, 2012, Article ID: 246725. https://doi.org/10.1155/2012/246725

[87] Marques, D.R., Gomes, A.A., Clemente, V., et al. (2018) Self-Referential Dysfunction and Default-Mode Hyperactivation in Psychophysiological Insomnia Patients: A Case-Control fMRI Study. Journal of Psychophysiology, 32, 140-155. https://doi.org/10.1027/0269-8803/a000194

[88] Holmes, E.A. and Mathews, A. (2010) Mental Imagery in Emotion and Emotional Disorders. Clinical Psychology Review, 30, 349-362. https://doi.org/10.1016/j.cpr.2010.01.001

[89] Brewin, C.R., Gregory, J.D., Lipton, M. and Burgess, N. (2010) Intrusive Images in Psychological Disorders: Characteristics, Neural Mechanisms, and Treatment Implications. Psychological Review, 117, 210-232. https://doi.org/10.1037/a0018113

[90] Nelson, J. and Harvey, A.G. (2003) Pre-Sleep Imagery under the Microscope: A Comparison of Patients with Insomnia and Good Sleepers. Behaviour Research and Therapy, 41, 273-284. https://doi.org/10.1016/S0005-7967(02)00010-4

[91] Brewin, C.R. (2014) Episodic Memory, Perceptual Memory, and Their Interaction: Foundations for a Theory of Posttraumatic Stress Disorder. Psychological Bulletin, 140, 69-97. https://doi.org/10.1037/a0033722

[92] Foa, E.B., Steketee, G., Turner, R.M. and Fischer, S.C. (1980) Effects of Imaginal Exposure to Feared Disasters in Obsessive-Compulsive Checkers. Behaviour Research and Therapy, 18, 449-455. https://doi.org/10.1016/0005-7967(80)90010-8

[93] Holmes, E.A., Arntz, A. and Smucker, M.R. (2007) Imagery Rescripting in Cognitive Behaviour Therapy: Images, Treatment Techniques and Outcomes. Journal of Behavior Therapy and Experimental Psychiatry, 38, 297-305. 
https://doi.org/10.1016/j.jbtep.2007.10.007

[94] Hirsch, C.R., Clark, D.M., Mathews, A. and Williams, R. (2003) Self-Images Play a Causal Role in Social Phobia. Behaviour Research and Therapy, 41, 909-921. https://doi.org/10.1016/S0005-7967(02)00103-1

[95] Damasio, A.R. (1999) The Feeling of What Happens: Body and Emotion in the Making of Consciousness. Harcourt, Orlando, FL.

[96] Revonsuo, A. (2006) Inner Presence: Consciousness as a Biological Phenomenon. MIT Press, Cambridge, MA.

[97] Blanke, O. and Metzinger, T. (2009) Full-Body Illusions and Minimal Phenomenal Selfhood. Trends in Cognitive Sciences, 13, 7-13. https://doi.org/10.1016/j.tics.2008.10.003

[98] Trehub, A. (2007) Space, Self, and the Theater of Consciousness. Consciousness and Cognition, 16, 310-330. https://doi.org/10.1016/j.concog.2006.06.004

[99] Smythies, J.R. (2003) Space, Time and Consciousness. Journal of Consciousness Studies, 10, 47-56.

[100] Metzinger, T. (2003) Being No-One. MIT Press, Cambridge, MA.

[101] Siegel, S. (2006) Direct Realism and Perceptual Consciousness. Philosophy and Phenomenological Research, 73, 378-410. https://doi.org/10.1111/j.1933-1592.2006.tb00623.x

[102] Hesslow, G. (2002) Conscious Thought as Simulation of Behaviour and Perception. Trends in Cognitive Sciences, 6, 242-247. https://doi.org/10.1016/S1364-6613(02)01913-7

[103] Grush, R. (2004) The Emulation Theory of Representation: Motor Control, Imagery, and Perception. Behavioral and Brain Sciences, 27, 377-442. https://doi.org/10.1017/S0140525X04000093

[104] Maldonato, M. and Dell'Orco, S. (2012) The Predictive Brain. World Futures, 68, 381-389. https://doi.org/10.1080/02604027.2012.693846

[105] Engel, A.K., Fries, P. and Singer, W. (2001) Dynamic Predictions: Oscillations and Synchrony in Top-Down Processing. Nature Reviews Neuroscience, 2, 704-716. https://doi.org/10.1038/35094565

[106] Strauch, I. and Meier, B. (1996) In Search of Dreams. Results of Experimental Dream Research. SUNY Press, New York.

[107] Driver, J. and Vuilleumier, P. (2001) Perceptual Awareness and Its Loss in Unilateral Neglect and Extinction. Cognition, 79, 39-88. https://doi.org/10.1016/S0010-0277(00)00124-4

[108] Oizumi, M., Albantakis, L. and Tononi, G. (2014) From the Phenomenology to the Mechanisms of Consciousness: Integrated Information Theory 3.0. PLoS Computational Biology, 10, e1003588. https://doi.org/10.1371/journal.pcbi.1003588

[109] Jerath, R. and Beveridge, C. (2019) Multimodal Integration and Phenomenal Spatiotemporal Binding: A Perspective from the Default Space Theory. Frontiers in Integrative Neuroscience, 13, 2. https://doi.org/10.3389/fnint.2019.00002

[110] Fingelkurts, A.A. and Fingelkurts, A.A. (2001) Operational Architectonics of the Human Brain Biopotential Field: Towards Solving the Mind-Brain Problem. Brain and Mind, 2, 261-296. https://doi.org/10.1023/A:1014427822738

[111] Jerath, R., Beveridge, C. and Jensen, M. (2019) On the Hierarchical Organization of Oscillatory Assemblies: Layered Superimposition and a Global Bioelectric Framework. Frontiers in Human Neuroscience, 13, 426. https://doi.org/10.3389/fnhum.2019.00426 
[112] Sirota, A. and Buzsaki, G. (2005) Interaction between Neocortical and Hippocampal Networks via Slow Oscillations. Thalamus \& Related Systems, 3, 245-259. https://doi.org/10.1017/S1472928807000258

[113] Canolty, R.T., Edwards, E., Dalal, S.S., et al. (2006) High Gamma Power Is Phase-Locked to Theta Oscillations in Human Neocortex. Science, 313, 1626-1628. https://doi.org/10.1126/science.1128115

[114] Schroeder, C.E. and Lakatos, P. (2009) Low-Frequency Neuronal Oscillations as Instruments of Sensory Selection. Trends in Neurosciences, 32, 9-18. https://doi.org/10.1016/j.tins.2008.09.012

[115] Vanhatalo, S., Palva, J.M., Holmes, M.D., et al. (2004) Infraslow Oscillations Modulate Excitability and Interictal Epileptic Activity in the Human Cortex during Sleep. Proceedings of the National Academy of Sciences of the United States of America, 101, 5053-5057. https://doi.org/10.1073/pnas.0305375101

[116] Steriade, M. (2006) Grouping of Brain Rhythms in Corticothalamic Systems. Neuroscience, 137, 1087-1106. https://doi.org/10.1016/j.neuroscience.2005.10.029

[117] Monto, S., Palva, S., Voipio, J. and Matias Palva, J. (2008) Very Slow EEG Fluctuations Predict the Dynamics of Stimulus Detection and Oscillation Amplitudes in Humans. Journal of Neuroscience, 28, 8268-8272. https://doi.org/10.1523/JNEUROSCI.1910-08.2008

[118] Fingelkurts, A.A. and Fingelkurts, A.A. (2017) Information Flow in the Brain: Ordered Sequences of Metastable States. Information, 8, 22. https://doi.org/10.3390/info8010022

[119] Hyafil, A., Giraud, A.-L., Fontolan, L. and Gutkin, B. (2015) Neural Cross-Frequency Coupling: Connecting Architectures, Mechanisms, and Functions. Trends in Neurosciences, 38, 725-740. https://doi.org/10.1016/j.tins.2015.09.001

[120] Harris, K.D., Csicsvari, J., Hirase, H., Dragoi, G. and Buzsáki, G. (2003) Organization of Cell Assemblies in the Hippocampus. Nature, 424, 552-556. https://doi.org/10.1038/nature01834

[121] Isbell, L.A. (2006) Snakes as Agents of Evolutionary Change in Primate Brains. Journal of Human Evolution, 51, 1-35. https://doi.org/10.1016/j.jhevol.2005.12.012

[122] Öhman, A., Flykt, A. and Esteves, F. (2001) Emotion Drives Attention: Detecting the Snake in the Grass. Journal of Experimental Psychology: General, 130, 466-478. https://doi.org/10.1037/0096-3445.130.3.466

[123] Shibasaki, M. and Kawai, N. (2009) Rapid Detection of Snakes by Japanese Monkeys (Macaca fuscata): An Evolutionarily Predisposed Visual System. Journal of Comparative Psychology, 123, 131-135. https://doi.org/10.1037/a0015095

[124] Van Le, Q., Isbell, L.A., Matsumoto, J., et al. (2013) Pulvinar Neurons Reveal Neurobiological Evidence of Past Selection for Rapid Detection of Snakes. Proceedings of the National Academy of Sciences of the United States of America, 110, 19000-19005. https://doi.org/10.1073/pnas.1312648110

[125] Van Strien, J.W., Christiaans, G., Franken, I.H.A. and Huijding, J. (2016) Curvilinear Shapes and the Snake Detection Hypothesis: An ERP Study. Psychophysiology, 53, 252-257. https://doi.org/10.1111/psyp.12564

[126] Purves, D., Augustine, G.J., Fitzpatrick, D., et al. (2018) Memory. In: Neuroscience, Sinauer Associates, New York, 682.

[127] Bonmati-Carrion, M.A., Arguelles-Prieto, R., Martinez-Madrid, M.J., et al. (2014) Protecting the Melatonin Rhythm through Circadian Healthy Light Exposure. International Journal of Molecular Sciences, 15, 23448-23500. 
https://doi.org/10.3390/ijms151223448

[128] Fourtassi, M., Rode, G. and Pisella, L. (2017) Using Eye Movements to Explore Mental Representations of Space. Annals of Physical and Rehabilitation Medicine, 60, 160-163. https://doi.org/10.1016/j.rehab.2016.03.001

[129] Damasio Antonio, R., Everitt Barry, J., Bishop, D., et al. (1996) The Somatic Marker Hypothesis and the Possible Functions of the Prefrontal Cortex. Philosophical Transactions of the Royal Society of London. Series B: Biological Sciences, 351, 1413-1420. https://doi.org/10.1098/rstb.1996.0125

[130] Wilson, R.A. and Foglia, L. (2017) Embodied Cognition. In: The Stanford Encyclopedia of Philosophy, Metaphysics Research Lab, Stanford University, Stanford, CA.

[131] Miglis, M.G. (2016) Autonomic Dysfunction in Primary Sleep Disorders. Sleep Medicine, 19, 40-49. https://doi.org/10.1016/j.sleep.2015.10.001

[132] Barrett, L.F., Mesquita, B., Ochsner, K.N. and Gross, J.J. (2007) The Experience of Emotion. Annual Review of Psychology, 58, 373-403.

https://doi.org/10.1146/annurev.psych.58.110405.085709

[133] Damasio, A. and Carvalho, G.B. (2013) The Nature of Feelings: Evolutionary and Neurobiological Origins. Nature Reviews Neuroscience, 14, 143. https://doi.org/10.1038/nrn3403

[134] Purves, D., Augustine, G.J., Fitzpatrick, D., et al. (2018) Emotion. In: Neuroscience, Sinauer Associates, New York. 